FOCUSED DISCUSSION: Scientific Expertise (invited paper)

\title{
Wild or Farmed? \\ Seeking Effective Science in a Controversial Environment
}

\author{
Stephen Bocking*
}

Arguments implicating nature and science can arise in the most unlikely places. At the supermarket smoked salmon awaits shoppers: chinook salmon from British Columbia, and Atlantic salmon from B.C., New Brunswick, or Norway. They are priced the same, and look similar, but embedded in their diverse provenance is a controversy thirty years in the making. The "wild" chinook salmon were caught in the open ocean; the "farmed" Atlantic salmon were raised in pens in coastal inlets. The distinction has spawned an intense debate over salmon farming (also known as aquaculture)-nowhere more so than in British Columbia.

In some ways this coastal controversy is unique, epitomizing the symbolic significance of all things marine to British Columbians. But it shares a crucial feature with other controversies, such as those involving genetically modified organisms, nanotechnology, or climate change. Since the debate began, science has played an essential role as a source of information and authority. Scientific knowledge and practice can be said to have contributed to creating the controversy, have added to its intractability, and, perhaps hold some keys to its resolution.

The controversy has certainly proven intractable. In May 2007 a special committee of the B.C. Legislature presented its report on the salmon farming industry, but after 18 months of study the committee failed even to find agreement among its members. Charged with building a common vision for the industry's future, it instead reproduced the polarized debate that divides British

\footnotetext{
* Stephen Bocking is professor of environmental policy and history at Trent University. Since graduating from the Institute for the History and Philosophy of Science and Technology, University of Toronto, in 1992 he has published more than two dozen academic articles and chapters, as well as two books: Ecologists and Environmental Politics: A History of Contemporary Ecology (Yale University Press, 1997), and Nature's Experts: Science, Politics, and the Environment (Rutgers University Press, 2004). He has also published various edited collections, including a theme issue of the Urban History Review on Canadian urban environmental history (2005), a theme issue of the Journal of Canadian Studies on science and politics in Canada (2002), and Biodiversity in Canada: Ecology, Ideas, and Action (Broadview Press, 2000). His research now focuses on the political roles and implications of scientific expertise. Projects underway include a study of the recent history of environmental science in northern Canada, and a study of the science and politics of salmon aquaculture. He also teaches courses on the politics of environmental science, environmental issues in the developing world, Canadian environmental policy, environmental history, and the university environment.
}

Spontaneous Generations 1:1 (2007). ISSN 1913-0465. University of Toronto 
Columbians.

Such outcomes testify to the challenges posed by contentious issues involving scientific expertise. To resolve such controversies, what is needed is not just more science, still less a rejection of science altogether, but a new social contract between science and society, founded on an understanding of the political dimensions of expertise.

\section{Aquaculture's origins}

Salmon farming began unobtrusively in B.C. In the early 1970s a few coastal folk began experiments with raising salmon in small net-cages, using surplus eggs from coastal hatcheries. For several years it remained a cottage industry-some sites not much more than logs hammered together, with nets suspended beneath, located at sites chosen mostly for ease of access. A great deal of trial and error ensued: working out the best feeds, methods for controlling diseases, and optimal environmental conditions. The industry grew slowly, and in 1984 ten farms produced only 107 tonnes. Then, however, the industry took off. By 1988, 118 farms were producing 6600 tonnes, and three years later production had quadrupled to 24000 tonnes. During these years the importing and raising of Atlantic salmon was approved. It was faster-growing and more docile than Pacific salmon, but an exotic species that would also provoke controversy. As conflicts with other uses of the coastal environment multiplied, the industry also shifted to the north-to deeper, colder, more isolated waters. But the industry was fragile: in the late 1980s salmon prices fell, many farms failed, and ownership became more concentrated-a trend that has continued. Today four multinational corporations, most headquartered in Norway, own 80 percent of the roughly 100 farms scattered along the coast. In 1998 farmed salmon production exceeded the wild salmon catch, and by 2002 it had reached 84000 tonnes.

The science of salmon farming lagged behind this growth. As I have already noted, for years knowledge was mostly gained through trial and error. Techniques and information were also borrowed from other places, including Norway and Scotland, that had longer experience with the industry. This transfer would raise persistent questions regarding the relevance of such knowledge to conditions in BC.

By the late 1990s many observers were noting large gaps in scientific understanding of the industry and its impacts. In response the federal Department of Fisheries and Oceans launched large research programs. These tended, however, to focus on industry priorities: how to make fish grow faster, enhance their marketability, and control diseases; in short, how to make the industry more competitive. Belatedly, and at least in part in response to criticisms that it had an inadequate knowledge base with which to ensure that salmon farms could co-exist with wild salmon, the department began studies of 
the industry's environmental impacts, often in collaboration with academics, including scientists at the University of British Columbia's Centre for Aquaculture and the Environment. Overall, Department of Fisheries and Oceans research, along with the regulatory activities of the provincial Ministry of Agriculture and Lands, has exemplified (in keeping with Max Weber's observations) how an administrative agency employs expert knowledge as the basis of bureaucratic authority.

There has also emerged, however, a network of scientists, in universities and public interest organizations, that have provided a contrasting perspective, one more focused on the impacts of salmon farming on wild salmon and their ecosystems. Their work, often tied to organizations like the David Suzuki Foundation and the Raincoast Research Society (led by Alexandra Morton, perhaps the most influential independent scientist on the coast), exemplifies, particularly in comparison with research by the federal agency, how research can have embedded within it particular perspectives and values regarding our relations with nature.

This history has also been marked by a series of public inquiries intended to gather knowledge, canvass opinions, and establish consensus on the industry's prospects and conflicts. Some have been initiated by public interest organizations or academic institutions, such as the Suzuki Foundation's Leggatt Inquiry in 2001, and Simon Fraser University's Speaking for the Salmon forum. The province itself has conducted several official inquiries, most often when the controversy has become especially intense. The Gillespie Inquiry of 1986, the Salmon Aquaculture Review of 1997, the B.C. Pacific Salmon Forum that began its work in 2005, and the Special Committee of the Legislature that reported this year, all exemplify, as did periodic moratoria on new salmon farms, efforts to stabilize the issue. Their intention has been, in the midst of heated argument, to rein in the controversy, recreating the conditions in which conventional regulatory authorities (the province and the Department of Fisheries and Oceans) could once again assert their authority over decisions.

Yet events have consistently intervened to subvert such efforts. Often, the intervention has been by the local environment itself. Since 2000 there have been a series of unexpected observations: that escaped Atlantic salmon are able to colonize the Pacific coast; that farmed salmon concentrate contaminants in their flesh; and that farms incubate sea lice, and then transfer the parasite to young wild salmon. Collectively, such events have shown how novel technologies and ecologies, like salmon farms, can open up new areas of uncertainty and ignorance. They also demonstrate the status of other species as actors in environmental history and the history of science.

However, these events should not have been so surprising. The history of BC salmon farming - like the history of other controversies involving technology and nature-has unfolded at the confluence of destabilizing transformations not just in nature itself, but also in how we understand natural phenomena, and how we make collective decisions. The cognitive shift has been evidenced by the 
newfound and widely held skepticism towards the notion itself of scientific objectivity-an attitude also applied to decisions, like those made by administrative agencies, that are justified on the basis of science. The political change has been the declining authority of nation-states, and the shift towards a new politics of pluralism, in which authority is dispersed across diverse institutions and communities, compelling changes in roles, and new relationships of collaboration or antagonism.

Such is the landscape, formed in recent history, of contemporary debates over salmon farming: a transformed environment, the presence of industry itself, as well as the institutions that promote, regulate, study and criticize it-a landscape of contention existing at the intersection of ecology, economics and politics. More intangible, but quite real, is the accumulated experience: a contested knowledge base, attitudes of skepticism and trust, and an entrenched polarization between advocates and opponents. History itself has become a matter of contention: some view a transition from wild to farmed salmon as essential and inevitable, akin to the long-ago shift from hunting to agriculture; arrayed against this vision is that of wild salmon as essential to coastal identity, history and heritage, requiring protection against that recent interloper, the Atlantic salmon.

\section{Controversy}

The most visible arguments about salmon farms concern their environmental impacts. Essentially feedlots gone to sea, they produce large quantities of waste-faeces, uneaten feed and dead fish-cascading to the seafloor below. Sea lice multiply in farms and spread to wild salmon, and toxic contaminants are a concern, including the pesticides used to control lice and the antibiotics feed to the salmon (farms crowded with fish are ideal incubators of disease). Escaped Atlantic salmon threaten to displace fragile stocks of wild salmon. Salmon pens attract sea lions and seals, trapping and drowning large numbers.

Farm operators and advocates contest all these claims. They argue that wellrun farms pose limited risk, with pesticides and drugs used strictly in moderation. Few salmon escape, and those that do pose no threat to wild salmon. Problems with sea lice infecting wild salmon can be addressed by siting farms appropriately. Stronger nets promise to protect sea lions from their own appetites.

In all these debates environmental knowledge is strongly evident. Science has been used by all parties, not just as a source of information about risks and benefits, but as a source of authority. Both those who favour farming and those who are opposed invoke science to support their arguments, their framing of the issue (as a question of managing an economically valuable, environmentallysound activity, or conversely, of protecting wild salmon stocks from a hazardous industry), and their claims to be presenting an objective, impartial perspective. 
Advocates invoke science in different ways. Politicians and others who speak for the farming industry tend to express confidence in the capacities of expertbased institutions. In contrast, their opponents more often cite the testimony of individual scientists willing to challenging institutional authority. This negotiation of science and its diverse meanings takes place in many fora: not only scientific reports, but the media, public inquiries, and elaborate websites. The prominence of science testifies to how politics - the processes by which society engages in collective debate and decision-making-encompasses the generation and use of knowledge.

Those invoking science do so with the goal of shifting the controversy to a desirable conclusion: acceptance of the industry; or its transformation, and if necessary, closure. Yet neither outcome has occurred, demonstrating how scientific information alone rarely ends a debate, especially when the stakes are high.

Nature helps ensure this stalemate: in the face of complex and changing ecosystems, our knowledge must always be incomplete, uncertain, and riddled with ignorance. The boundaries of scientific disciplines and incomplete theories impose additional obstacles to understanding. And salmon farming itself, like other technological interventions into nature, such as genetic engineering, by creating new phenomena also creates new mysteries. Uncertainties are also often magnified by advocates themselves, illustrating how uncertainty is not discovered, but constructed.

When there is uncertainty and ignorance-whether these are the product of nature or of human action-there will always be more than one plausible interpretation of available data. In such circumstances opposing interests and scientists will invoke whatever interpretation is most compatible with their expectations and interests.

Accentuating the challenges of uncertain science are questions of trust-a perennial issue in risk controversies. In the midst of public debate, establishing trust becomes less a matter of evaluating researchers' methods or reliability, than of considering their institutions and their history. So it has been with the Department of Fisheries and Oceans. In February 2001 the federal Auditor General reported that, contrary to its own claims, the department lacked the capacity to both regulate salmon farms and meet its obligations under the Fisheries Act to protect wild salmon and their habitat. Many critics also see a conflict of interest in the department's efforts to both promote and regulate the industry - a situation familiar to observers of the forestry, oil and gas, and biotechnology industries. In practice, the department has acted most zealously as a promoter, viewing farmed salmon as the wave of the future. Yves Bastien, its Aquaculture Commissioner, in 1999 boldly stated that, "I am absolutely convinced that when our descendants look back... they will view the dawn of the third millennium as the point at which mankind went from fishing to aquaculture." In the eyes of its critics, such attitudes cannot but influence the department's assessment of evidence regarding the impacts and viability of the 
industry. Those who speak for the industry, however, return the favour by casting aspersions on the results obtained by scientists that receive funding from environmental organizations.

As corporate relationships become more important, universitiestraditionally considered the appropriate site for impartial inquiry-have become embroiled in these calculations of trust. Units that work closely with industry, such as U.B.C.'s Centre for Aquaculture and the Environment, exemplify how private interests can influence the scientific agenda, directing inquiry away from basic research or the public interest, towards innovation for private gain. The influence of private interests on the interpretation and communication of research results-most evident in such areas as drug research and genetic engineering-similarly impedes trust in university research.

But the crucial challenge relates to the nature of the issues at stake. These may be debated in scientific language, but much more is on the table than empirical questions. Roiling these debates are contrasting visions of nature and the human presence: of the future of the coast envisioned in terms of an expanding farming industry, integrated into global markets; or as one in which wild salmon and ecosystems flourish, protected from industrial threats. These views are also expressed in contrasting approaches to doing science-through the pursuit of more efficient farming methods, or through study of the hazards these farms pose to wild salmon-and to interpreting scientific information: on the basis of a precautionary approach, or guided by a willingness to accept and manage uncertain and unknown risks. These contrasting perspectives on the conduct and interpretation of science exemplify the co-production of natural and social orders, in which knowledge embodies beliefs not only about how the world is, but how it ought to be.

Controversies, when knowledge and meaning are unstable and under negotiation, provide rich material for scholars. They are opportunities to examine how scientific knowledge is constructed, and how the relations between knowledge, nature, and the values and interests of society are negotiated. These episodes also make evident the significance of institutions in structuring the relations between science and society. Through their policies and statements institutions embody particular roles and meanings, with their choices to promote, question, or deliberate on new technologies shaped by their own histories and identity.

Controversies, when all parties are seeking to persuade others of their views of nature and science, also make evident the significance of framing. Through frames-ideas about entities and causal relationships, constructed from diverse materials: scientific information, local knowledge, ethical values, and economic interests-people and institutions make sense of what they see around them, shaping their understanding of what is real and requires a policy response. The importance of frames especially becomes apparent when novel information 
elicits contradictory responses. That farmed salmon production now exceeds the wild salmon catch suggests progress to some, but to others indicates an unbalanced coastal ecosystem and economy; sea lions trapped and dying in a salmon farm is either a regrettable but manageable problem, or a sign of the technology's ecological toxicity.

Controversies can destabilize and reconstitute even those categories commonly taken as foundational in political and social analysis. They provide thereby opportunities to examine how these categories are constructed. Arguments regarding the implications of aquaculture range from the varied meanings of food-matters of personal health and nutrition, as well as questions of provenance, authenticity, and integrity-to the global consequences of the industry's demand for meal made from fish captured a hemisphere away. Defining the "environment" that is at stake thus becomes itself a matter of debate. Similarly, the identity of "science" - and the boundaries distinguishing it from other forms of knowledge-are challenged when research is dismissed as corrupted by values and interests, or is displaced by local knowledge gained through daily experience. As the authority of regulatory agencies is renegotiated, and arguments continue over their appropriate scale and responsibilities, the notion of the "state" itself is also reconsidered. And finally, when the controversy ranges far beyond provincial boundaries-to the Norwegian headquarters of farming corporations, chefs in seafood restaurants across North America, or readers of The New York Times (the target of a recent activist campaign)-then the "society" on whose behalf decisions are made is rendered entirely ambiguous.

\section{Old and new social contracts}

Controversies involving science provide many opportunities for scholarly study, but also at stake is the practical matter of how science can be applied effectively to our relations with nature. Studies in history, philosophy, and sociology have demonstrated that science is not simply a source of objective facts. Can it nevertheless find an appropriate role, enabling institutions and society to learn about the world, and to act effectively on this knowledge?

Effective science in the context of controversy is not just a matter of more studies, communicated more effectively. Controversies like that involving aquaculture-in which the available information is often uncertain, or is considered untrustworthy, and is also wrapped up in debates about such matters as the future of the coastal environment-cannot be resolved simply through additional research. Yet the debate nevertheless depends on the best available knowledge about the environment.

Over the last sixty years two social contracts have dominated the relation between society and the scientific community. One is that of basic research, in which scientists pursue questions defined and disciplined by their own curiosity and training, with their results evaluated by their peers. Historically this contract has been underwritten by agencies like the National Science Foundation and the 
Natural Sciences and Engineering Research Council of Canada. More recently (especially in Canadian science policy), we have seen the emergence of "innovation research", in which scientists are tied to industry priorities, pursuing knowledge less for its own sake than for the promise of new and saleable technologies.

Both contracts have their place. Yet they also fail to capture the complexity of contemporary relations between science and society. Research guided by either contract can increase the uncertainty of our knowledge of the world and expand areas of ignorance, whether by failing to take up questions that lack theoretical significance, or by focusing too narrowly on priorities defined by economic possibilities. Both approaches have also proven unable to avoid the conundrum commonly seen in controversies, in which competing scientific perspectives become themselves the focus of debate. When that happens, there are commonly two outcomes, evident in controversies ranging from salmon farming, to climate change, to genetic engineering. First, those resisting the implications of research will tend to dismiss science as merely an instrument in the service of its patrons, or as a realm in which the claims of opposing experts cancel each other out. And second, the real issues at stake-conflicting economic interests, concerns regarding environmental impacts, or competing visions for the future of ecosystems and communities-will be neglected. As many controversies have shown, reasonable argument and agreement on a course of action are impossible in the absence of facts accepted by all parties.

These outcomes, when science proves unable to contribute to resolving a controversy, suggest the need for a new contract between it and society. This contract would encompass novel ways of setting research priorities, assuring the quality of knowledge, and communicating and applying this knowledge.

A fundamental objective of this new social contract would be to enable the construction of knowledge considered credible by all parties. Such knowledge could forestall endless arguments regarding the uncertainties embedded in almost any research result, enabling debate to focus instead on the issues actually at stake. This credibility can be assured in several ways. Peer reviewfamiliar in basic research, and also now often used in regulatory contexts, and by environmental organizations seeking to enhance confidence in their arguments-can play an important role. Peer review is not infallible, especially in practical contexts, but its value can be enhanced by understanding that it serves best not necessarily by assuring the truth of scientific results, but by fulfilling the function of "witnessing" research, helping to ensure its quality and rigor. This function, in turn, implies reconsidering the structure of the review process: relying less on individual reviewers than on groups of independent experts, and widening participation beyond the scientific community, to include, for example, holders of local knowledge. 
A related requirement is for research to be considered legitimate, with its purposes understood by all parties, and ties to any interest groups clearly evident. This can be assured through transparent arrangements for funding science and for determining research objectives. It also means open and inclusive negotiation of how knowledge is to be used-whether, say, risks and benefits are to be balanced, or the precautionary principle is to be applied. Such arrangements would acknowledge that the legitimacy of research, like credibility, is achieved not by applying universal norms of scientific conduct, but through a context-dependent process that takes into account local interests and concerns.

Science must also be effective, which means solving problems and advancing the policy agenda. This entails fulfilling a diversity of roles, from anticipating emerging issues, to addressing those with which we are already familiar. And this, in turn, requires a very broad definition of relevance, to be achieved, as philosophers of science such as James Brown have argued, through a pluralistic research strategy. Such a strategy would draw on a diversity of participants in setting research priorities-acknowledging, in particular, the essential role that independent scientists like Alexandra Morton have played in broadening the salmon farming research agenda. Effective science is also a matter of genuine, two-way communication between scientists and those who use scientific information-a true dialogue, ensuring that research is not only relevant, but that its results are communicated in ways consistent with public concerns and perspectives on nature and the world. Only through such dialogue are scientific assessments likely to be sensitive to political realities, and political decisions likely to be scientifically realistic.

These requirements demand new institutions for science, able to encompass the diverse interests and perspectives that are in play in any complex controversy, providing the arena for a true competition of ideas. "Boundary organizations" like the Intergovernmental Panel on Climate Change can fulfil a useful role: straddling the intersection of science and politics, they can stabilize the border between these realms by asserting their credibility and legitimacy in both.

Signs of movement towards this new contract for science are becoming evident in the salmon farming controversy: in cooperative research efforts that bring together industry and environmentalists, or environmentalists with academic scientists; in the work of a few agencies like the Pacific Salmon Forum; and in requirements that all results of research and monitoring be made public. These experiments should be taken further, guided by explicit agreements reached beforehand as to the procedures to be followed in setting scientific priorities, conducting research, and evaluating and applying the results. 
If controversies like that involving salmon farming-or any other contentious technology-are ever to be resolved, it will only be on the basis of knowledge accepted by all parties. This requirement demands closer attention to how science is done, by whom, and for whose interests. This suggests an important agenda-theoretically interesting and practically useful-for science and technology studies.

STEPHEN BOCKING

Trent University

\section{References}

These references provide more information on the salmon farming issue, and on more general issues relating to science in controversies:

Bocking, Stephen. 2004. Nature's experts: Science, politics, and the environment. New Jersey: Rutgers University Press.

British Columbia, Legislative Assembly. May 2007. Special Committee on Sustainable Aquaculture. Final Report. www.leg.bc.ca/cmt/38thparl/session3/aquaculture/index.htm.

Guston, David. 2000. Between politics and science: Assuring the integrity and productivity of research. Cambridge: Cambridge University Press.

Hume, Stephen et al. 2004. A stain upon the sea: West Coast salmon farming. Madeira Park: Harbour Publishing.

Jasanoff, Sheila. 2005. Designs on nature: Science and democracy in Europe and the United States. New Jersey: Princeton University Press.

Kitcher, Philip. 2001. Science, truth and democracy. New York: Oxford University Press.

Naylor, Rosamund and Marshall Burke. 2005. Aquaculture and ocean resources: Raising tigers of the sea. Annual Review of Environment and Resources 30:185-218.

Robson, Peter A. 2006. Salmon farming: The whole story. BC: Heritage House.

Simon Fraser University. January 2007. Speaking for the Salmon Forum. Convener's Report, Summit of Scientists on Aquaculture and the protection of Wild Salmon on the British Columbia Coast. www.sfu.ca/cstudies/science/aquaculture2007.htm.

Wynne, Brian. 1996. Misunderstood misunderstandings: Social identities and public uptake of science, In Misunderstanding science? The public reconstruction of science and technology, ed. Alan Irwin and Brian Wynne, 1946. Cambridge: Cambridge University Press. 